Article

\title{
Effects of Short-Term Laser Beam Heating on the Absorptivity of Steel Sheets
}

\author{
Helge Kügler $D$ \\ BIAS—Bremer Institut für angewandte Strahltechnik GmbH, 28359 Bremen, Germany; kuegler@bias.de; \\ Tel.: +49-421-218-58117
}

Received: 15 April 2019; Accepted: 9 May 2019; Published: 14 May 2019

\begin{abstract}
The efficiency of laser beam processes basically depends on the efficiency of the laser beam source and the efficiency of the irradiated material's energy absorption. This absorptivity can be influenced by the surface condition. Besides coating or boundary layers, the surface topography is decisive. In this study, the effects of various time-temperature distributions on the absorptivity changes of steel sheets were investigated. For this purpose, three steels were chosen, namely, a stainless steel, a spring steel, and a hot work tool steel. Pre- and post-process characterizations of the absorptivity and surface topography were performed. Controlled heating with a laser beam was carried out using temperatures between 700 and $1200{ }^{\circ} \mathrm{C}$ and durations between 2 and $34 \mathrm{~s}$. In order to compare the influences of these heating procedures on the absorptivity, a characteristic value, the temperature-compensated time, was introduced. It is shown that the surface roughness was influenced by laser irradiation but inadequately describes the increase of absorptivity. The changes in absorptivity are attributed to oxidation, which had an influence on the topography in a sub-micrometer range. Moreover, a saturation effect is observed for intense heatings. Furthermore, it is shown that the temperature-compensated time is a suitable value to describe absorptivity changes caused by short-term heating.
\end{abstract}

Keywords: absorption coefficient; laser beam processing; process efficiency; metal heating

\section{Introduction}

Laser beam sources are widely used in current production applications. For material processing, the efficiency of the laser beam process is determined by the absorption of the radiation by the irradiated material. The absorptivity of a material depends amongst other things on the laser beam wavelength, the material, and its surface topography. Measuring this absorptivity was first carried out using a calorimetric approach with thermocouples [1]. Those studies have shown the strong influence of coatings on absorptivity, which is challenging for laser-based surface heat treatments such as laser beam hardening. The absorption of steel during irradiation with laser radiation of different wavelengths was analyzed by Dausinger and Shen [2]. They found that the absorption of $1 \mu \mathrm{m}$ laser radiation of iron for heating up to the melting point decreases with increasing temperatures, whereas $\mathrm{CO}_{2}$ laser radiation increases with higher temperatures.

Furthermore, the influence of the surface structure was investigated. On the one hand, it is generally known that rougher surfaces have a higher absorptivity [3]. Therefore, metals can be grinded or particle blasted as a pre-treatment to increase the absorptivity [4]. However, on the other hand, several studies have shown that conventional roughness values like $R a, R q$, and $R z$ are not suitable for directly predicting the absorptivity of a metal surface. For example, specimens having comparable roughness values showed differing absorptivity [3]. In addition, peak values of absorptivity were determined between 2 and $4 \mu \mathrm{m}$ for the maximum surface height $(R z)$ [3]. Instead of using these conventional roughness values, it was suggested to use the mean slope of the surface profile [5]. 
Another approach to characterizing the effect of roughness on the absorptivity of radiation was proposed by Agababov [6]. A form factor was defined that divided the area size of a smooth surface corresponding to the area of the measuring field by the surface of the actual roughness geometry. According to radiation measurements with a pyrometer, the absorptivity of radiation was increasing with lower form factors. In addition, it was found that mean square roughness values did not satisfactorily reflect the absorption changes, explained by the missing consideration of the shape, structure, and distribution of the roughness [6].

The surface structure of steel sheets can also be modified by oxidation which is caused by heating under an oxygen-containing atmosphere. Early investigations showed the influence of lower temperatures up to $650{ }^{\circ} \mathrm{C}$ and holding times of $0.5 \mathrm{~s}$ to 200 days on the oxidation of several steels [7]. Based on time and temperature parameters, the colors straw, blue, and brown can be predicted to appear on the surface. For the stainless steel 1.4301, investigations of the oxidation process showed that the annealing color represents the oxide layer thickness [8]. After heating at $650{ }^{\circ} \mathrm{C}$ for $7 \mathrm{~min}$, the surface turned blue and no change in the oxide layer thickness was observed for up to $10 \mathrm{~min}$. That blue color was determined to be $130 \mathrm{~nm}$ to $140 \mathrm{~nm}$ thick [9]. These annealing colors can also be used for controlled surface coloring (e.g., [10]).

During the oxidation of the material $304 \mathrm{~L}$, mixed iron-chromium oxides (spinel) are formed at room temperature, whereas iron-rich oxides result after a $2 \mathrm{~min}$ oxidation at $600 \mathrm{~K}$ without shielding gas [11]. Further investigations mention chromium oxide growth for the heating of AISI 304 at $850^{\circ} \mathrm{C}$ [12]. These findings were confirmed for the oxidation of stainless steel in air plasma [13]. In the range of 900 to $1100{ }^{\circ} \mathrm{C}$, the material 1.4301 mainly forms $\mathrm{FeCr}_{2} \mathrm{O}_{4}$ spinel [14]. Generally, the oxidation behavior of stainless steel can be described with the parabolic law [15]. However, investigations of diffusion processes in vacuum indicate the formation of a healing layer at the grain boundaries which modifies the rate law [16]. This is more pronounced the higher the chromium content and the annealing times; no deviation from the parabolic law was measured for up to $30 \mathrm{~min}$ at $700{ }^{\circ} \mathrm{C}$ [16]. Additionally, the oxidation rate was found to be dependent on the grain size, with finer grains having a higher oxidation rate [17].

The oxidation of steel increases absorptivity, which is the reason why surfaces for laser heating are often coated with graphite to achieve a constant absorption during the heating process [4]. Oxidation was also found to be a dominant factor for absorptivity changes in investigations on the hardening of low-alloy steel [18]. However, the extent of absorptivity changes caused by short-term laser beam irradiation has been insufficiently studied.

In order to describe the relationship between material loads and material modifications, a process signature was defined [19]. That universal description provides information about the resulting surface and boundary zone properties, whereby the manufacturing process is irrelevant. With a process signature, a correlation between the load of a process and the resulting modification is drawn which enables the generation of surface integrity states based on knowledge [20]. This also enables substitutions of manufacturing processes by obtaining corresponding process signatures.

The generation of a process signature was carried out for a thermal-induced white layer formation in $42 \mathrm{CrMo} 4$ steel [21]. It was shown that a certain temperature field diameter represents a process signature for laser-chemical machining in different media, argon and sodium nitrate in this case. That characteristic value had not yet been described for the absorptivity changes caused by thermal influences on steel sheet surfaces.

\section{Research Aim and Scope}

For this paper, the absorptivity changes of steel sheet surfaces by short-term laser beam heating were investigated. Furthermore, a characteristic value describing the influences of different time-temperature distributions was calculated to allow the identification of absorptivity changes in several applications. 


\section{Materials and Methods}

\subsection{Materials}

For these investigations, three different steel sheets were used, namely, the stainless steel X5CrNi18-10 (1.4301), the spring steel C75S+LC (1.1248), and the hot work tool steel X40CrMoV5-1 (1.2344). The sheet thickness was $3.0 \mathrm{~mm}$ for the stainless steel (1.4301) and the spring steel (1.1248). The tool steel specimens (1.2344) were machined from a block to a thickness of $4.0 \mathrm{~mm}$. The materials were cut into specimens of $50 \times 76 \mathrm{~mm}^{2}$. Compositions of the steels used are listed in Table 1 .

Table 1. Material compositions.

\begin{tabular}{|c|c|c|c|c|c|c|c|c|c|c|c|}
\hline Material & & $\mathrm{C}$ & Si & Mn & $\mathbf{P}$ & $\mathrm{S}$ & $\mathrm{Cr}$ & $\mathbf{N i}$ & Mo & $\mathbf{V}$ & $\mathbf{N}$ \\
\hline 1.4301 & $\min$. & & & & & & 17.5 & 8 & & & \\
\hline (X5CrNiMo18-10) & $\max$ & 0.07 & 1 & 2 & 0.045 & 0.03 & 19.5 & 10.5 & & & 0.1 \\
\hline \multirow{2}{*}{1.1248 (C75S+LC) } & $\min$. & 0.7 & 0.15 & 0.6 & & & & & & & \\
\hline & $\max$ & 0.8 & 0.35 & 0.9 & 0.025 & 0.025 & 0.4 & 0.4 & 0.1 & & \\
\hline \multirow{2}{*}{1.2344 (X40CrMoV5-1) } & $\min$. & 0.35 & 0.8 & 0.25 & & & 4.8 & & 1.2 & 0.85 & \\
\hline & $\max$ & 0.42 & 1.2 & 0.5 & 0.03 & 0.03 & 5.5 & & 1.5 & 1.15 & \\
\hline
\end{tabular}

\subsection{Experimental Setup and Program}

Each specimen was characterized prior to and after a specific temperature treatment with a multi-kW laser. This characterization included roughness and absorption measurements.

A disc laser (Trumpf TruDisk 12002, TRUMPF GmbH + Co. KG, Ditzingen, Germany; wavelength: $1030 \mathrm{~nm}$, BPP: 8 mm*mrad, NA: 0.1) and a laser optic (Trumpf BEO D70); collimation length $200 \mathrm{~mm}$, focal length $300 \mathrm{~mm}$, Rayleigh length: $2.298 \mathrm{~mm}$ ) were used for the laser beam heating setup. The maximum laser power was limited to $8 \mathrm{~kW}$ due to the limits of the optical components. Tryouts were done with a $50 \mathrm{~mm}$ defocused laser beam, resulting in a measured spot size of $6.3 \mathrm{~mm}$.

In order to ensure a constant temperature during the desired processing time, a closed-loop control for the frequency of laser pulses was used. The laser power was set to $500 \mathrm{~W}$ for all experiments. The pulse duration was $6 \mathrm{~ms}$ with a controlled frequency in the range of 0 to $100 \mathrm{~Hz}$.

Several time-temperature curves were obtained in order to investigate the effects of different temperature impacts as well as holding times on the absorption of the sheet surface. Laser processing was carried out with varying temperature target values from 700 to $1200{ }^{\circ} \mathrm{C}$ for the stainless steel (1.4301) and 700 to $900{ }^{\circ} \mathrm{C}$ for the materials 1.1248 and 1.2344. The duration of laser heating was varied between 2 and $34 \mathrm{~s}$. Additionally, a heating-up time of $2 \mathrm{~s}$ was applied for each target temperature. Additionally, increasing temperature intervals $\left(700^{\circ} \mathrm{C} \rightarrow 800^{\circ} \mathrm{C} \rightarrow 900^{\circ} \mathrm{C}\right)$ with constant $(2 \mathrm{~s}$ each, $5 \mathrm{~s}$ each, $10 \mathrm{~s}$ each) as well as varying time steps (e.g., $2 \mathrm{~s} \rightarrow 5 \mathrm{~s} \rightarrow 10 \mathrm{~s}$ ) were investigated.

Every parameter set was carried out three times. Processing was carried out at ambient atmosphere and without shielding gas.

\subsection{Temperature Measurements and Analyses}

During the punctual laser irradiation of the steel sheet surface, the surface temperature was measured with a digital two-color pyrometer (LumaSense Technologies IMPAC IGAR 12-LO, LumaSense Technologies GmbH, Frankfurt, Germany). The measuring range extended from 500 to $2200^{\circ} \mathrm{C}$.

For the comparability of time and temperature effects, a characteristic value was calculated which characterized the time-temperature curve including the heating and cooling phases. Such a parameter has already been defined as temperature-compensated time $\left(t_{c}\right)$ for the description of diffusion processes in powder metallurgy [22], as shown in Equation (1): 


$$
t_{c}=\int_{0}^{t} D_{0} e^{-\frac{Q_{e f f}}{k T_{a}(\bar{t})}} d \bar{t}
$$

This calculation contains the prefactor of the diffusion coefficient $D_{0}$, the activation energy $Q_{e f f}$, the Boltzmann constant $k$, as well as the time-temperature distribution $T_{a}(t)$. The value is indicated in the unit $m^{2}$, which at first seems unusual. However, the temperature-compensated time $\left(t_{c}\right)$ can be illustrated by considering the equation for the penetration depth $x$ of a diffusion process:

$$
x=\sqrt{2 D_{e f f} t}=\sqrt{2 t_{c}} .
$$

The temperature-compensated time can be determined by numerical integration of the temperature measurement signal and literature values for the activation energy $Q_{e f f}$ and the prefactor of the diffusion coefficient $D_{0}$. During the oxidation of the material 1.4301 in air, mainly $\mathrm{FeCr}_{2} \mathrm{O}_{4}$ spinel is formed in the temperature range of 900 to $1100{ }^{\circ} \mathrm{C}$ [14]. The literature values used for the diffusion of oxygen in $\gamma$-iron also differ only slightly from the characteristic values used for the diffusion of oxygen in chromium [23]. Therefore, the literature values for an oxygen diffusion into iron is used in this case [23].

In Figure 1, the integrated area for calculating the temperature-compensated time is marked in blue.

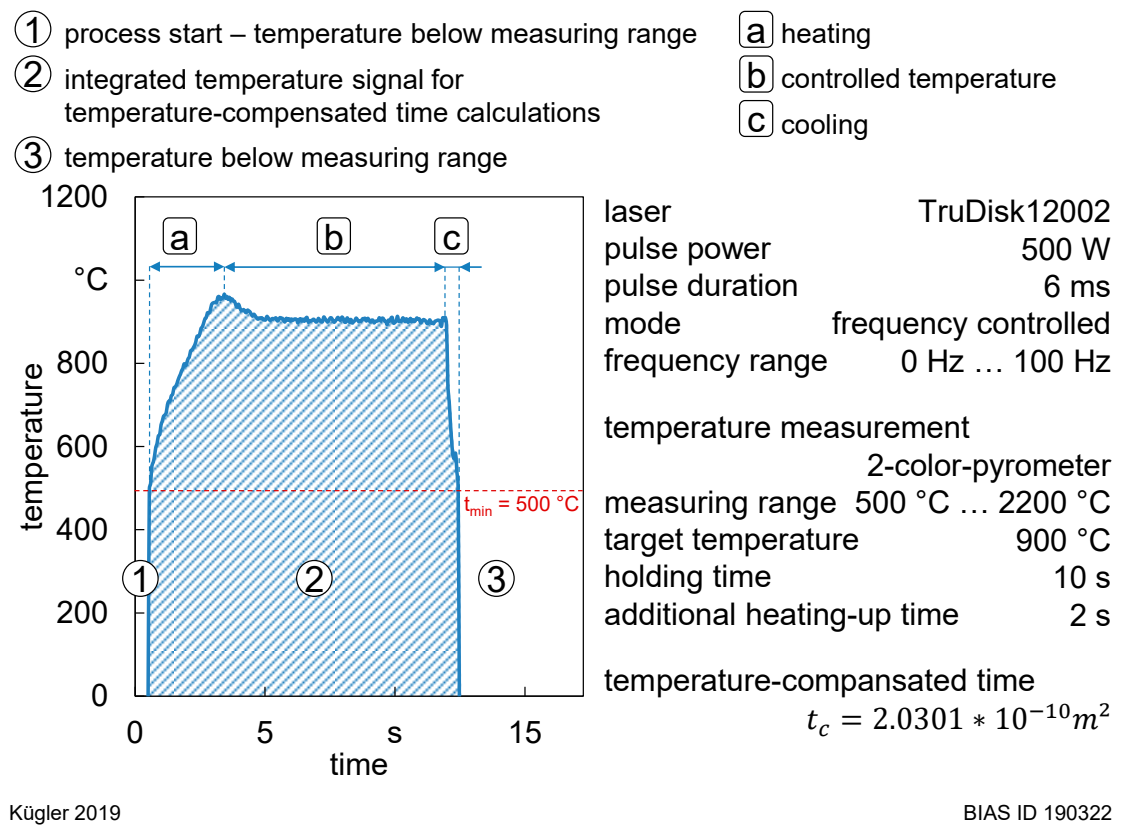

Figure 1. Example of temperature profile for the calculation of the temperature-compensated time.

\subsection{Absorption Measurement}

The absorption of each specimen was characterized using an integrating sphere $(\varnothing 100 \mathrm{~mm}$; $\mathrm{BaSO}_{4}$ coated; three ports) setup (see Figure 2). Irradiation of the specimen was carried out using a laser diode (Lumics LU1030M300, Lumics GmbH, Berlin, Germany) with a wavelength of $1030 \mathrm{~nm}$ and a maximum power of $300 \mathrm{~mW}$. This laser source was connected to the top port of the sphere with a Thorlabs CFC-2X-B collimator (Thorlabs GmbH, Dachau/Munich, Germany) with a focal length of $2 \mathrm{~mm}$ and a numerical aperture (NA) of 0.5. The measuring laser beam full-angle divergence with this collimator is indicated as $0.123^{\circ}$, resulting in an output waist diameter of $0.38 \mathrm{~mm}$ that is considered to be the spot size on the sheet surface. Metal sheets were applied at the second port of the sphere. This knife-edge port had an opening with a diameter of $5 \mathrm{~mm}$. Reflected radiation from the specimen was measured at the third port with a Si-photodiode (Thorlabs FDS100, Thorlabs $\mathrm{GmbH}$, Dachau/Munich, BY, Germany, rise time $=10 \mathrm{~ns})$. The measured radiation is assumed 
to be homogenized due to the coating of the sphere which is highly diffuse reflective. Therefore, measurements of the photo diode are considered to be representative. Measurements of an Nd:YAG mirror (Thorlabs NB07-K14, Thorlabs GmbH, Dachau/Munich, Germany) were used for calibration of the system. The reflectance of unpolarized laser radiation with a wavelength of $1030 \mathrm{~nm}$ and an irradiation angle of $8^{\circ}$ was $99.89369 \%$ according to its datasheet. Measurements of this mirror were set to this value.

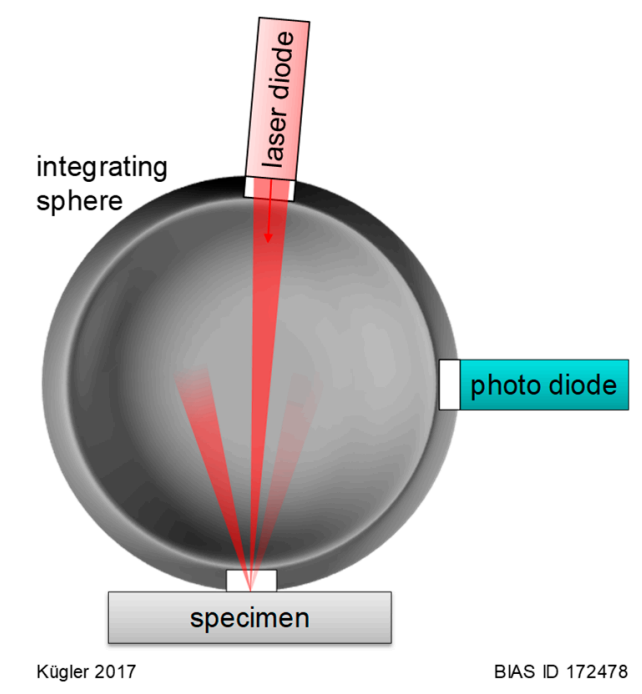

Figure 2. Schematic sketch of the measurement system for detecting the reflection share for determining the absorption of the irradiated specimen surface [24].

\subsection{Roughness Measurement}

For analyzing the roughness, the surface of each specimen was measured using a color 3D laser scanning microscope Keyence VK 9700 (KEYENCE DEUTSCHLAND GmbH, Neu-Isenburg, Germany). In this case, a $50 \times$ lens with an aperture of 0.55 was used, resulting in a measurement field of $184.9 \times 328.7 \mu \mathrm{m}^{2}$. Measured data were filtered with a Gaussian filter, an S-filter of $0.8 \mu \mathrm{m}$, and an L-filter of $0.5 \mathrm{~mm}$. Positioning of the roughness measuring was set concentrically to the laser interaction spot on the sheet surface.

For the characterization of the surface topography, surface roughness values for the arithmetical mean height $(S a)$, the root mean square height $(S q)$, and the maximum height $(S z)$ were determined according to ISO 25178. Additionally, the hybrid roughness value $S d q$, determining the root mean square gradient of slopes, and the topography factor surface/area were calculated. For this topography factor, the surface of the roughness profile is divided by the measurement field size mentioned above.

\subsection{SEM Analyses}

For high magnification imaging of the surface modifications resulting from laser irradiation, the scanning electron microscope (SEM) Zeiss EVO MA10 (Carl Zeiss Microscopy GmbH, Jena, Germany) was used. This device was equipped with a $\mathrm{LaB}_{6}$-cathode. For the investigations of surface modifications, secondary electron (SE) detection was used.

\section{Results}

For the analysis of the effects of short-term heating by laser irradiation, the initial states of the analyzed values must be measured. Therefore, the mean values of surface topography and absorption measurements of all untreated specimens are listed in Table 2 for each material.

During the irradiation process, no shielding gas was used. Therefore, laser irradiation resulted in a clearly visible color change which is attributed to oxidation. 
Table 2. Mean values of initial state specimens.

\begin{tabular}{ccccccc}
\hline Material & $S \boldsymbol{a}$ & $\boldsymbol{S} \boldsymbol{S}$ & $\boldsymbol{S z}$ & $\boldsymbol{S d q}$ & Surface/Area & Absorption \\
\hline 1.4301 & $0.84 \pm 0.08 \mu \mathrm{m}$ & $1.07 \pm 0.12 \mu \mathrm{m}$ & $14.54 \pm 3.01 \mu \mathrm{m}$ & $2.74 \pm 0.14$ & $5.52 \pm 0.25$ & $49.67 \pm 2.33 \%$ \\
1.1248 & $0.48 \pm 0.05 \mu \mathrm{m}$ & $0.64 \pm 0.08 \mu \mathrm{m}$ & $9.91 \pm 2.62 \mu \mathrm{m}$ & $2.19 \pm 0.49$ & $3.76 \pm 0.58$ & $45.82 \pm 3.64 \%$ \\
1.2344 & $1.93 \pm 0.76 \mu \mathrm{m}$ & $2.40 \pm 0.91 \mu \mathrm{m}$ & $21.56 \pm 5.32 \mu \mathrm{m}$ & $2.21 \pm 0.27$ & $3.97 \pm 0.62$ & $43.58 \pm 3.29 \%$ \\
\hline
\end{tabular}

Irradiations of the stainless steel sheets (1.4301) did not have a significant effect on the roughness values $S a$ and $S q$. For higher temperature-compensated times above $1000 \mu \mathrm{m}^{2}$, a slight reduction of these values can be observed (see Figure 3). This tendency is even more pronounced for the value $S z$.

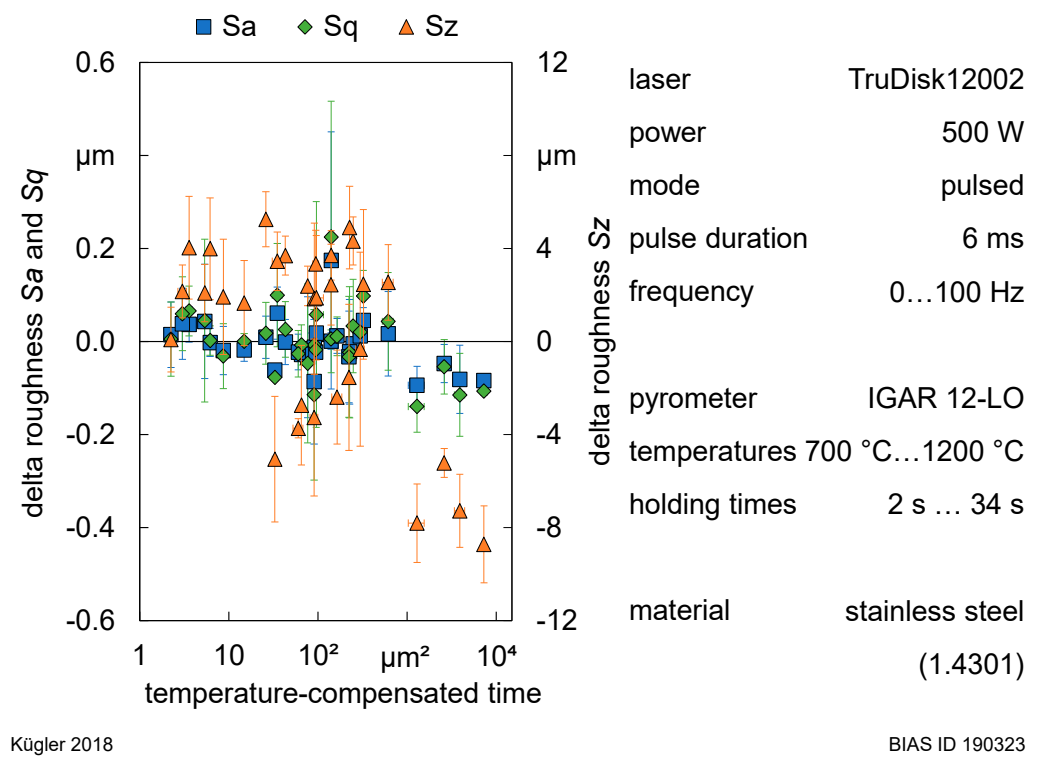

Figure 3. Roughness values $S a, S q$, and $S z$ of laser-heated 1.4301 sheets.

A similar progression can be observed for the hybrid roughness value $S d q$ (see Figure 4). The topography factor surface/area is slightly increased for increasing temperature-compensated times.

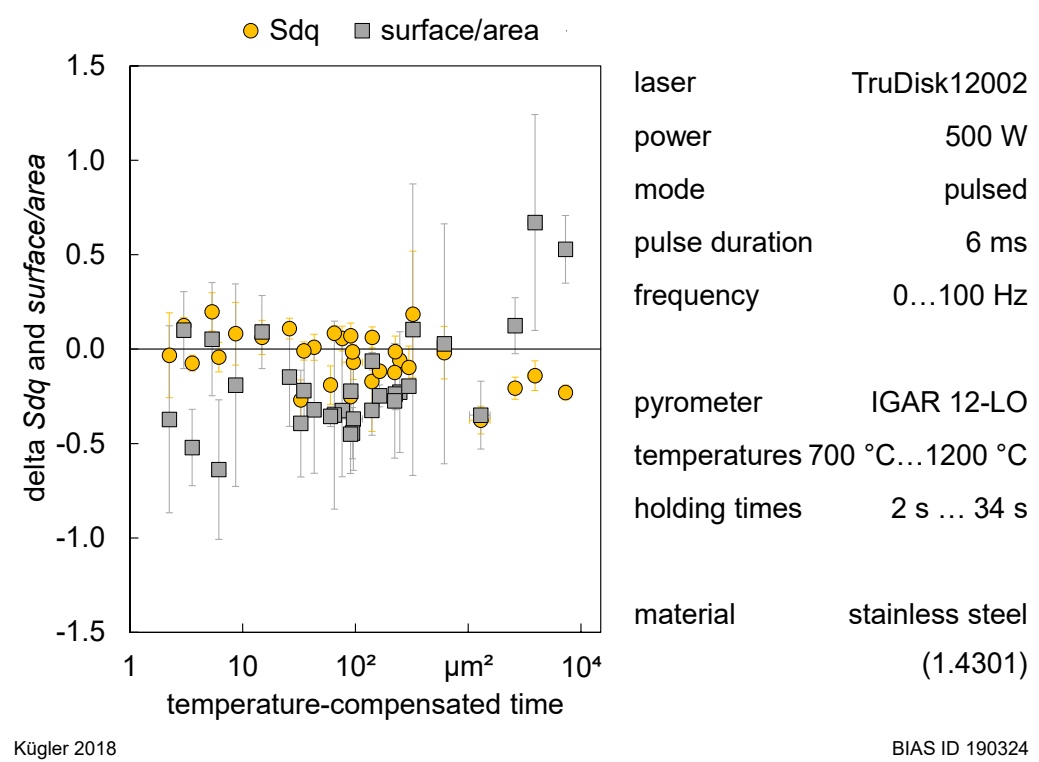

Figure 4. Roughness value $S d q$ and topography factor surface/area of laser-heated 1.4301 sheets. 
For the spring steel investigated in this study (1.1248), low irradiations, characterized by a low temperature-compensated time, led to a smoother surface in terms of lower $S a$ and $S q$ values (see Figure 5). Higher roughness values can only be identified for intense irradiations with temperature-compensated times over $250 \mu \mathrm{m}^{2}$. The maximum heights $(S z)$ of the laser-heated surfaces are almost identical to the initial state.

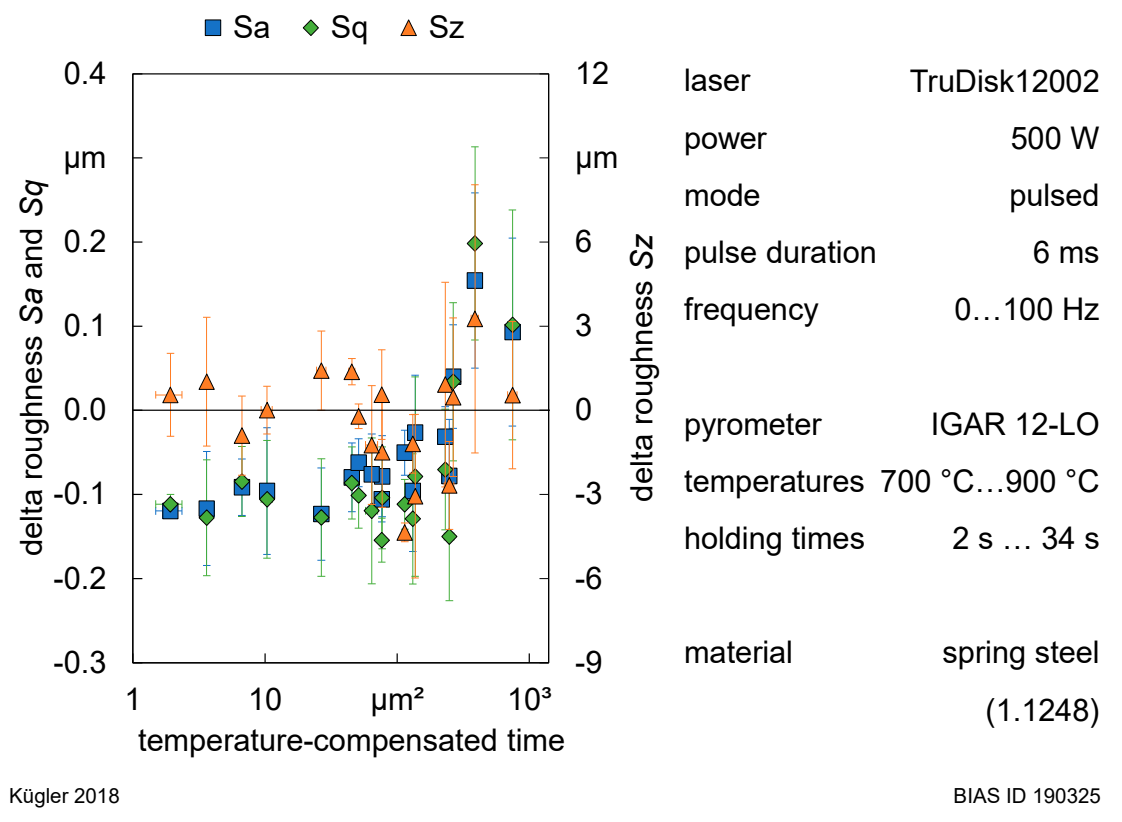

Figure 5. Roughness values $S a, S q$, and $S z$ of laser-heated 1.1248 sheets.

Both the changes in the hybrid roughness value $S d q$ and in the topography factor surface/area are increased with increasing temperature-compensated times (see Figure 6). However, it is noticeable that a reduction of these values can be observed for low temperature-compensated times. Changes in the topography factor surface/area are positive for temperature-compensated times over $50 \mu^{2}$. Sdq values are closer to the initial state the more intense is the heating.

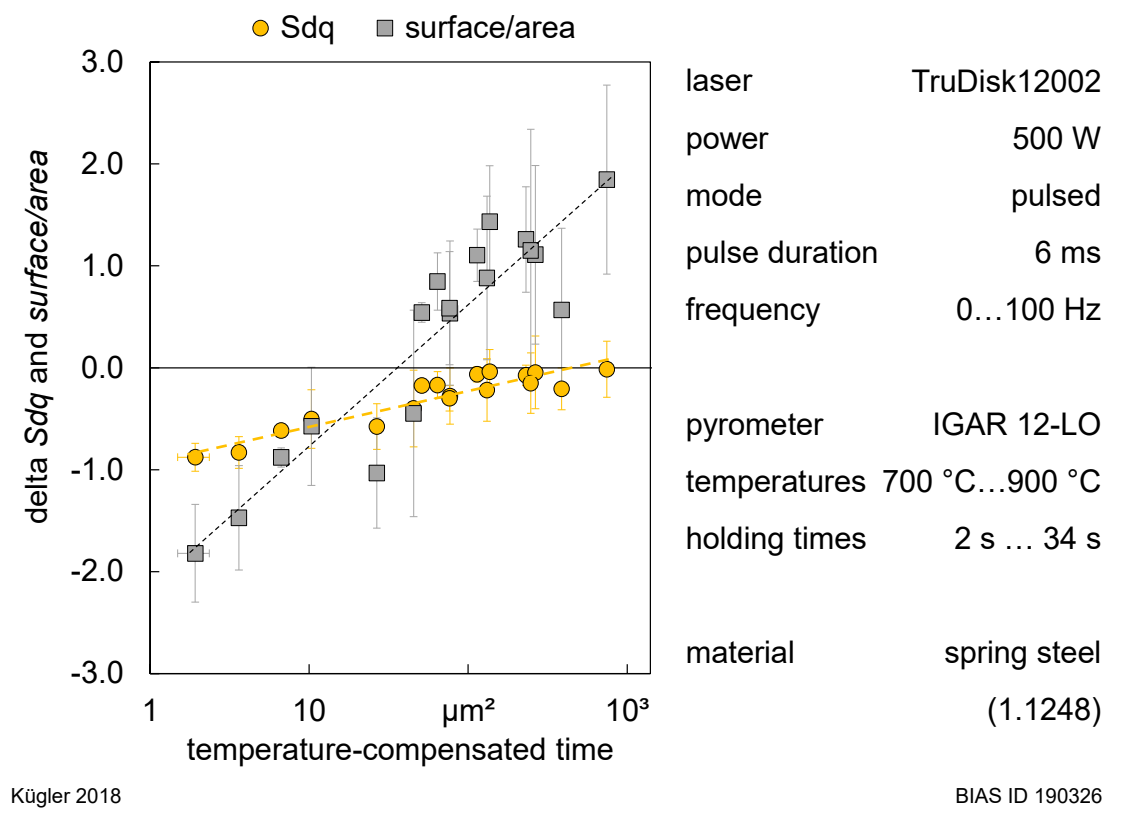

Figure 6. Roughness value $S d q$ and topography factor surface/area of laser-heated 1.1248 sheets. 
The roughness changes of the hot work tool steel (1.2344) induced by laser beam heating are shown in Figure 7. The mean values $S a$ and $S q$ are not significantly changed by laser irradiation, although there is an outlier with a decrease of the roughness and simultaneously high standard deviation at a temperature-compensated time of $61.84 \mu^{2}$. However, changes in the maximum height (Sz) of irradiated surfaces show a tendency to decrease with increasing temperature-compensated times.

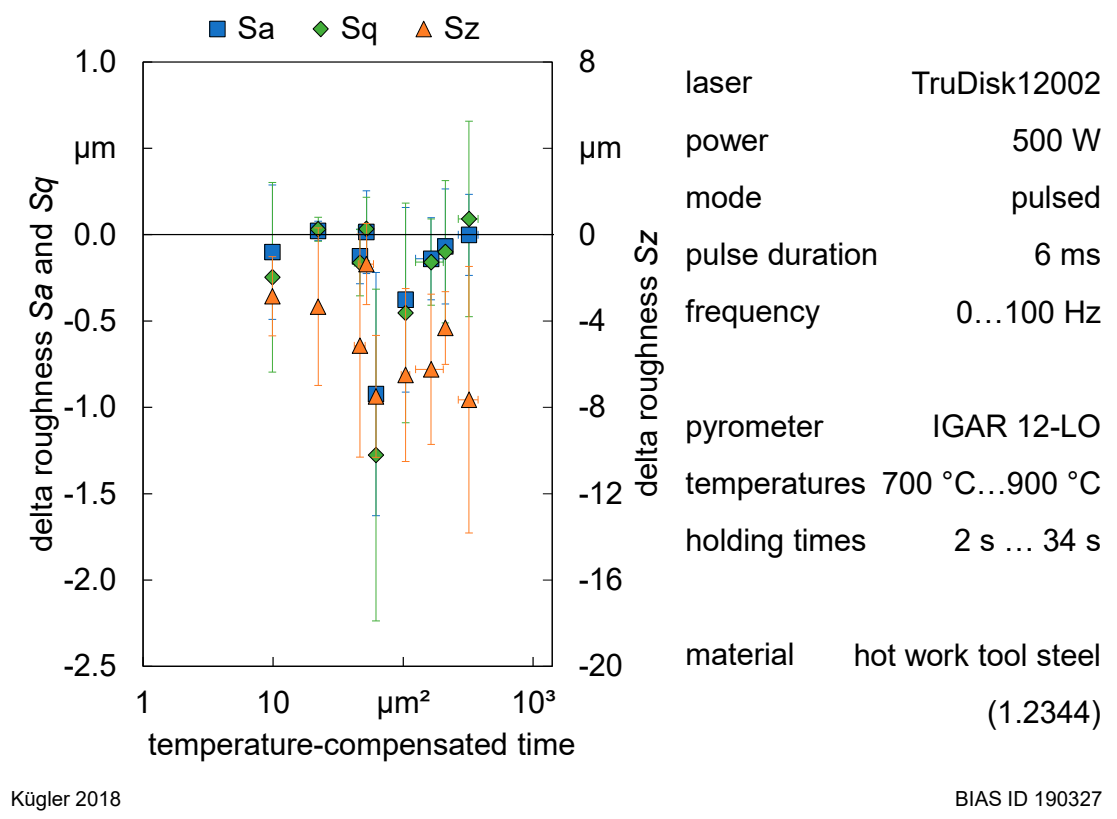

Figure 7. Roughness values $S a, S q$, and $S z$ of laser-heated 1.2344 sheets.

Short-term heating of the hot work tool steel (1.2344) seems to have no significant influence on the hybrid roughness value $S d q$ or the topography factor surface/area (see Figure 8). A significant increase of the topography factor surface/area can only be reported for a temperature-compensated time of $320.9 \mu \mathrm{m}^{2}$.

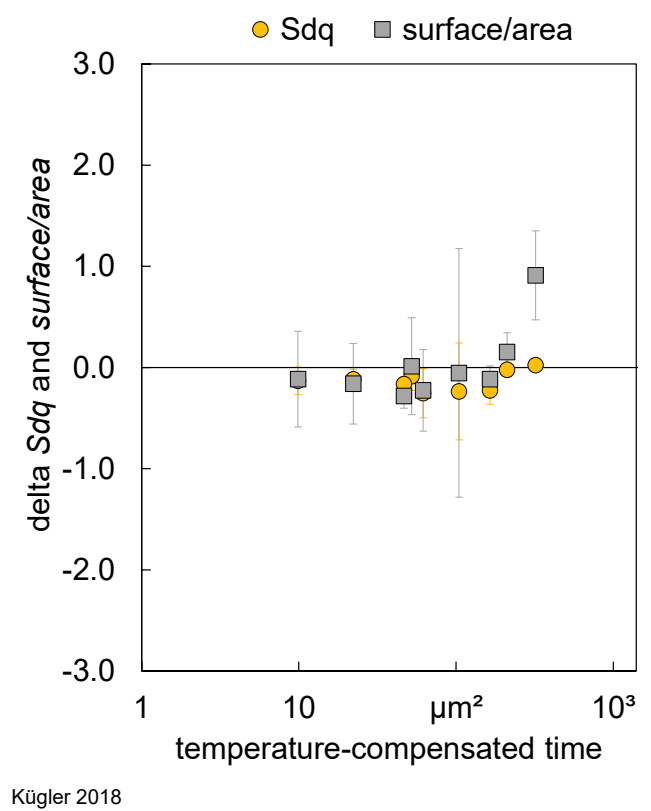

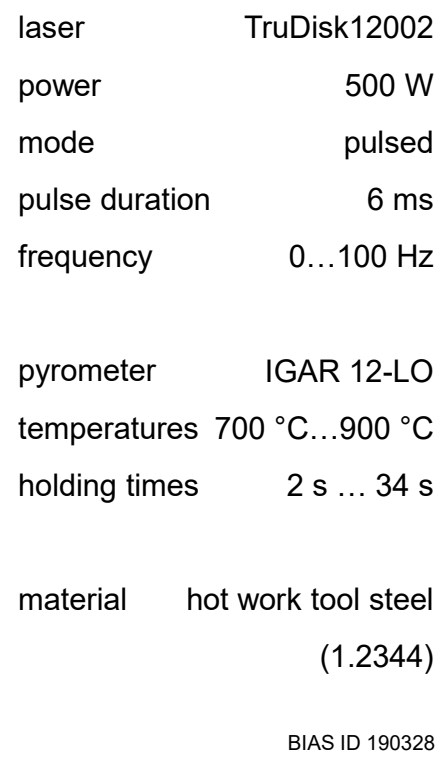

Figure 8. Roughness value $S d q$ and topography factor surface/area of laser-heated 1.2344 sheets. 
Overall, changes in the surface roughness values or the topography factor indicated by short-term heating with a laser beam do not indicate a clear tendency, although increased absorptivity values were measured after heating for all materials (see Figures 9 and 10). Generally, maximum surface height value changes $(S z)$ are more scattered compared to the changes in the mean roughness values $S a$ and $S q$ (see Figure 9).
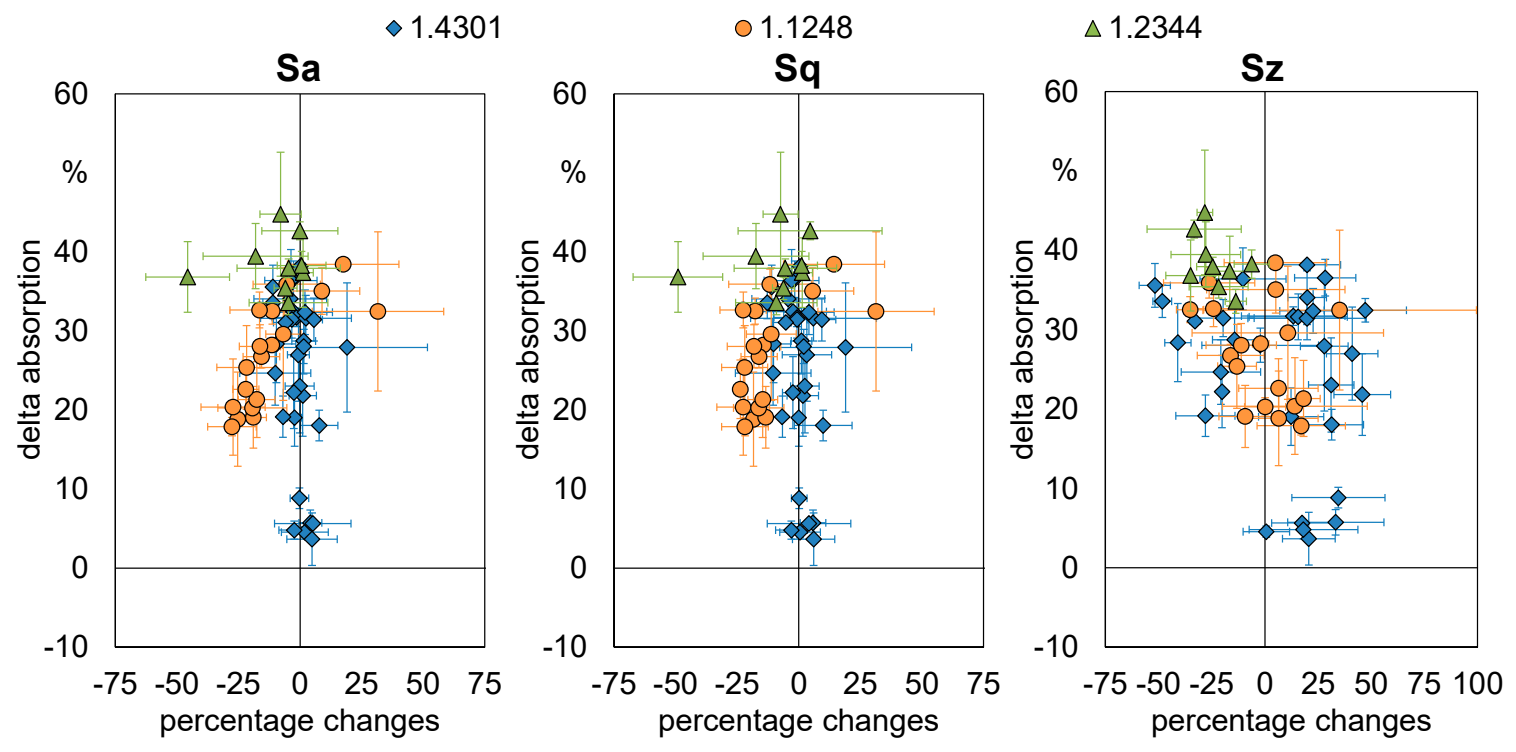

Kügler 2019

BIAS ID 190329

Figure 9. Influences of the roughness values $S a, S q$, and $S z$ on absorptivity changes of different steel sheets.

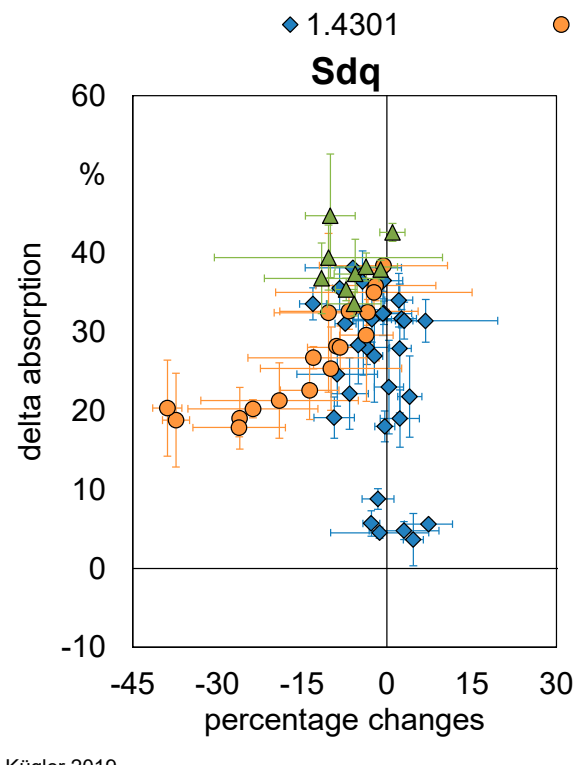

$$
01.1248 \quad \Delta 1.2344
$$

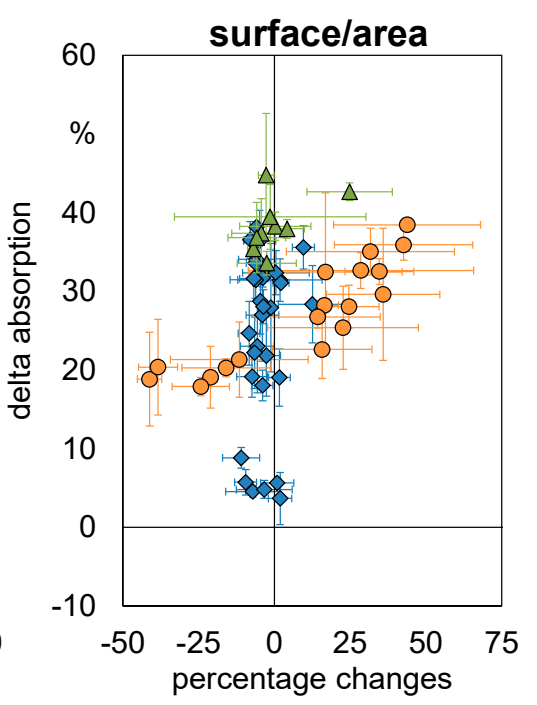

Kügler 2019

BIAS ID 190330

Figure 10. Influences of the roughness value $S d q$ and the topography factor surface/area on absorptivity changes of different steel sheets.

Influences of changes in the hybrid roughness value $S d q$ and the topography factor surface/area on the absorptivity are shown in Figure 10. For the stainless steel (1.4301) and the tool steel (1.2344), both increasing and decreasing values for $S d q$ and surface/area result in increased absorptivity. A tendency cannot be observed. 
For the spring steel (1.1248), increasing values for $S d q$ and surface/area correlate with increasing absorptivity. However, lower absorptivity changes around $20 \%$ relate to decreased values of $S d q$ and surface/area.

The influence of short-term heating on the surface structure at a sub-micrometer scale was investigated with SEM pictures (see Figure 11). Compared to the initial state, small particles can be observed on the surface of the material, which are considered to be oxides. Roughness of the specimen illustrated in Figure 11 is nearly not affected. Only the maximum height of the surface $(S z)$ is increased by $40 \%$. The reduction of the topography factor surface/area, however, is below $10 \%$.

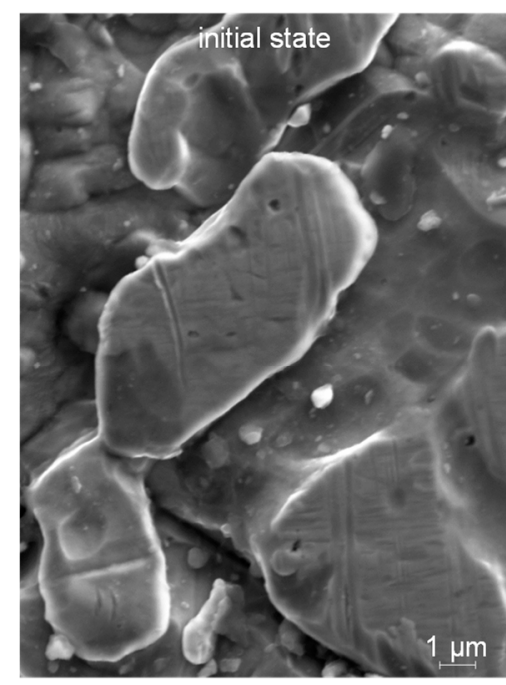

Kügler 2018

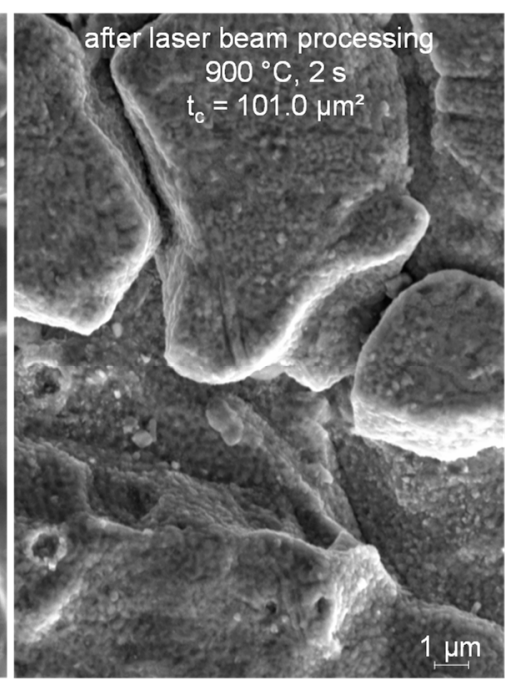

$\mu m_{1}$

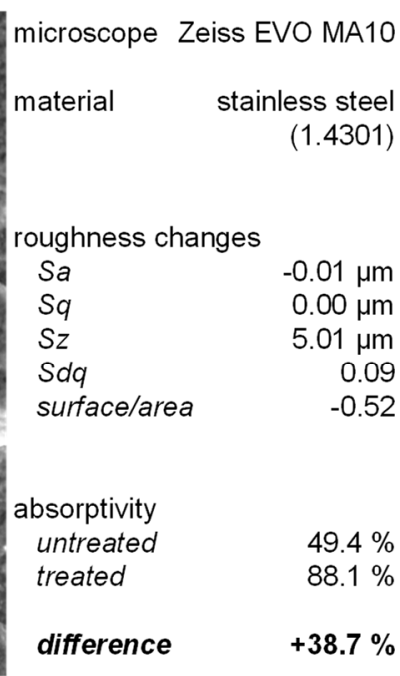

BIAS ID 190187

Figure 11. Visualization (secondary electron-scanning electron microscopy (SE-SEM)) of the oxide layer formation due to laser beam heating.

On the contrary, absorptivity is significantly increased by the laser beam heating of the specimen illustrated in Figure 11. In this case, heating with the parameters of a temperature of $900{ }^{\circ} \mathrm{C}$ for $2 \mathrm{~s}$ resulted in an absorptivity increase of $38.7 \%$.

The absorptivity changes of each material for all parameter sets are shown in Figure 12. The value of the temperature-compensated time is used to illustrate the influence of several time-temperature distributions on the absorptivity changes. In general, increasing temperature-compensated times increase the absorptivity. However, for the stainless steel (1.4301), temperature-compensated times over $323.2 \mu \mathrm{m}^{2}$ do not further increase the absorptivity compared to lower heating durations. It can be observed that even intense irradiations do not increase the total absorptivity over $87.5 \%$ in this study. This behavior indicates a state of saturation.

Changes in the absorptivity of the tool steel (1.2344) due to short-term heating are generally much more reactive. The described saturation level is already reached for lower temperature-compensated times of $9.88 \mu \mathrm{m}^{2}$. Further heating slightly further increases the absorptivity.

The spring steel (1.1248) shows comparable absorptivity changes as the stainless steel (1.4301) for temperature-compensated times of $26.7 \mu \mathrm{m}^{2}$ and higher. For lower temperature-compensated times, the change in absorptivity is more than double the change that occurs on the stainless steel (1.4301).

In order to describe the increasing absorptivity of the stainless steel (1.4301) by increasing temperature-compensated times, only short-term heating durations leading to increasing absorptivity up to a total absorption value of $80 \%$ are illustrated in Figure 13. It can be determined that the increasing absorptivity can be approximated by a logarithmic function. 


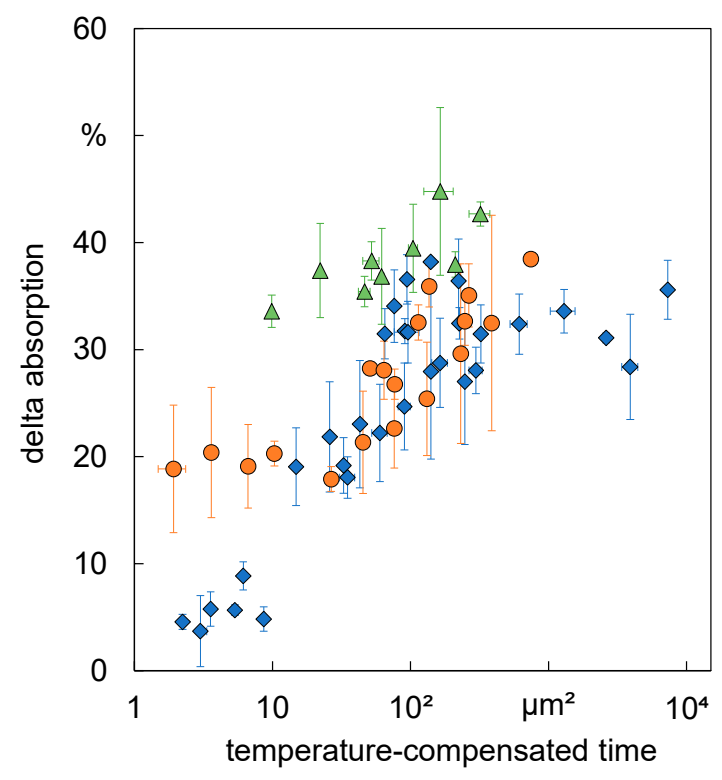

materials:

$\diamond 1.4301$

- 1.1248

$\triangle 1.2344$

Kügler 2018

BIAS ID 190331

Figure 12. Absorption changes due to laser beam heating.

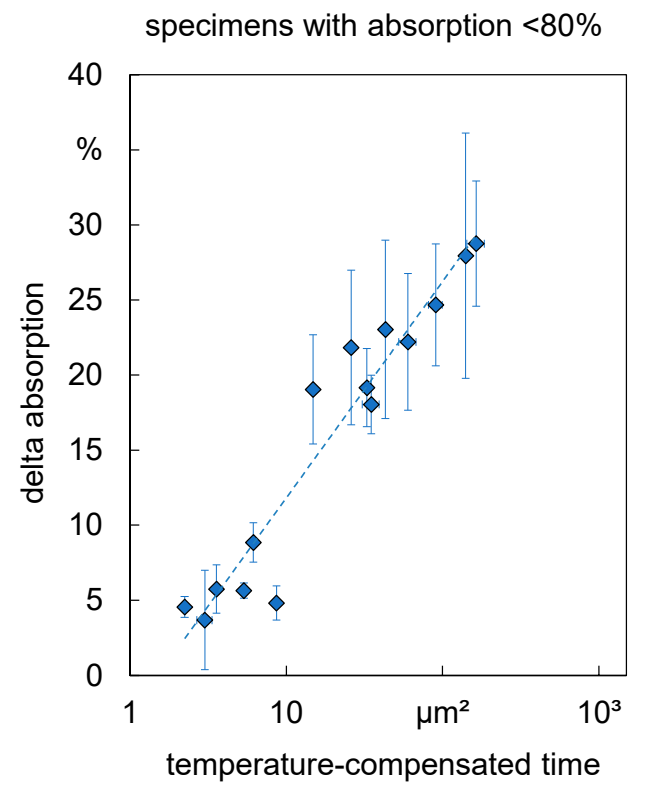

laser

TruDisk12002

power

$500 \mathrm{~W}$

mode

pulsed

pulse duration

$6 \mathrm{~ms}$

frequency

0...100 Hz

material

stainless steel

(1.4301)

regression

$$
y=6.26 \ln (x)-2.58
$$

coefficient of determination

$$
R^{2}=0.92
$$

Kügler 2018

BIAS ID 190332

Figure 13. Process signature of absorption changes induced by laser beam heating of the stainless steel sheets (1.4301).

\section{Discussion}

In this study, different alloys show comparable effects. The magnitude of absorptivity changes caused by short-term laser heating of the spring steel (1.1248) is comparable to that of the stainless steel (1.4301). The absorptivity changes of the tool steel (1.2344) reacts much faster to laser heating, which results in higher absorptivity changes when comparing the same irradiation conditions.

Investigations of the roughness prior to and after the laser heating indicate that absorptivity changes are not attributed to roughness changes induced by the short-term heating process (see Figure 9). The surface roughness values, like the conventional values (see Reference [3]), are not considered to be suitable to describe or predict the absorption of a metal surface, at least for the 
investigated steels. Instead of these roughness values, Bergström proposed considering the mean slope of a surface profile for the description of absorptivity [5]. However, the hybrid roughness value $S d q$, which is the root mean square gradient and therefore close to the proposal of Bergström, seems not to be suitable for absorptivity predictions, at least for the stainless steel (1.4301) and the tool steel (1.2344). For the spring steel (1.1248), there is a certain dependency. However, on the one hand, intensive irradiations causing high absorptivity changes result in negligible changes in the $S d q$ value (see Figure 10). On the other hand, low irradiation results in a reduction of the $S d q$ value. Therefore, further additional indicators are required to predict the absorptivity changes of the spring steel (1.1248) with this hybrid roughness factor.

Experiments by Agababov showed a higher degree of blackness for lower roughness factors, which was defined as measurement area divided by the roughness surface [6]. According to this, absorptivity should be increased with higher values of the topography factor surface/area. This topography factor increases for all materials used in this study when intense laser beam heating, in terms of a high temperature-compensated time, was carried out. However, absorptivity changes of 1.4301 and 1.2344 do not correlate with this topography factor (see Figure 10). For the steel 1.1248, higher topography factors led to higher absorptivity values, but lower laser irradiations showed reduced values for the topography factor (see Figure 6). Therefore, the theoretical relationship drawn by Agababov might be correct but is obviously counteracted by another effect.

A more detailed analysis of the surface changes induced by laser heating illustrates a structural change in the sub-micrometer range (see Figure 11). This indicates an oxide layer growth that is clearly affecting the absorptivity. However, this oxide layer is too small to have an influence on roughness values. Therefore, oxide layer thickness is assumed to be much smaller than the hundreds of nanometers quoted in investigations carried out by Junqueira et al. [9] who observed a significant difference due to the roughness of the oxide film. Investigations of oxide formations on the surface of stainless steel (see Reference [12]) report larger structures for similar temperatures but rather long heating times of 50 hours compared to the 2 seconds pictured in Figure 11.

On the one hand, roughness modifications of short-term laser heating did not correlate with the absorptivity changes found for irradiations of the steels mentioned. On the other hand, oxidation of the surface occurred due to the absence of shielding gas. Additionally, significant absorptivity changes were measured after laser irradiation. Therefore, the author ascribes oxidation as the dominating effect for increasing absorptivity, which confirms Pantsar and Kujanpää who found this for low-alloy steel [18]. Furthermore, a saturation effect can be observed especially for the stainless steel (1.4301). Since the parameter of the temperature-compensated time is based on material-specific diffusion parameters, there should be a causal relationship to the absorptivity changes for all specimens up to the state of saturation. This assumption is supported by the visualization of absorptivity changes of the stainless steel (1.4301) sheets with absorption values below $80 \%$ after laser irradiation (see Figure 13). The increasing absorption behavior can be described by a logarithmic regression function. The coefficient of determination is 0.92 for this correlation function, which underlines the significance of the temperature-compensated time at least for the stainless steel (1.4301).

Overall, the short-term heating via laser beam can be characterized by introducing the temperature-compensated time. With this characteristic value, absorption changes can be described for a certain material. The parameters of heating temperature and heating duration are combined into one characteristic value, whereby high temperatures with short durations result in the same absorptivity change as low temperatures with longer durations if the temperature-compensated time is the same. Therefore, the temperature-compensated time is a suitable value to represent a process signature, as defined by Brinksmeier et al. [19], for absorption changes caused by short-term heating.

\section{Conclusions}

For the three steels investigated in this study, the following effects of short-term laser beam heating were determined: 
- Surface modifications induced by short-term laser beam heating are insufficiently described by conventional roughness values.

- Conventional roughness values are inappropriate for indicating absorptivity changes due to a laser beam heating process. The topography factor surface/area indicates increased absorptivity caused by intense laser irradiation at least for the steel 1.1248.

- Absorptivity changes of the steels used in this study can be attributed to the growth of an oxide layer. However, a saturation effect occurs for intense laser irradiation.

- The value of a temperature-compensated time is suitable to describe influences of time-temperature distributions and their impact on the absorptivity change of steel sheets. Therefore, the temperature-compensated time is a suitable value to represent a process signature for absorption changes caused by short-term heating.

Funding: The author greatly acknowledges funding by the Deutsche Forschungsgemeinschaft DFG (project number 274609062).

Acknowledgments: The author wishes to thank Lukas Meluhn for performing parts of the experiments and measurements.

Conflicts of Interest: The author declares no conflict of interest.

\section{References}

1. Ricciardi, G.; Cantello, M. Laser Material Interaction: Absorption Coefficient in Welding and Surface Treatment. CIRP Ann. Manuf. Technol. 1994, 43, 171-175. [CrossRef]

2. Dausinger, F.; Shen, J. Energy Coupling Efficiency in Laser Surface Treatment. ISIJ Int. 1993, 33, 925-933. [CrossRef]

3. Seibold, G. Absorption technischer Oberflächen in der Lasermaterialbearbeitung (German); Herbert Utz Verlag: Munich, Germany, 2006; ISBN 3831606188.

4. Sainte-Catherine, C.; Jeandin, M.; Kechemair, D.; Ricaud, J.-P.; Sabatier, L. Study of Dynamic Absorptivity at $10.6 \mu \mathrm{m}\left(\mathrm{CO}_{2}\right)$ and $1.06 \mu \mathrm{m}$ (Nd-YAG) Wavelengths as a Function of Temperature. J. Phys. IV Colloque 1991, 01, C7-151-C7-157. [CrossRef]

5. Bergström, D. The Absorption of Laser Light by Rough Metal Surfaces. Ph.D. Thesis, Luleå University of Technology, Luleå, Sweden, February 2008.

6. Agababov, S.G. Effect of the roughness of the surface of a solid body on its radiation properties and methods for their experimental determination. High Temp. 1968, 6, 76-85.

7. McAdam, D.J.; Geil, G.W. Rate of oxidation of steels as determined from interference colors of oxide films. J. Res. Nat. Bur. Stand. 1939, 23, 63-124. [CrossRef]

8. Higginson, R.L.; Jackson, C.P.; Murrell, E.L.; Exworthy, P.A.Z.; Mortimer, R.J.; Worrall, D.R.; Wilcox, G.D. Effect of thermally grown oxides on colour development of stainless steel. Mater. High Temp. 2015, 32, 113-117. [CrossRef]

9. Junqueira, R.M.R.; Loureiro, C.R.d.O.; Andrade, M.S.; Buono, V.T.L. Characterization of interference thin films grown on stainless steel surface by alternate pulse current in a sulphochromic solution. Mater. Res. 2008, 11, 421-426. [CrossRef]

10. Veiko, V.; Odintsova, G.; Ageev, E.; Karlagina, Y.; Loginov, A.; Skuratova, A.; Gorbunova, E. Controlled oxide films formation by nanosecond laser pulses for color marking. Opt. Express 2014, 22, 24342-24347. [CrossRef] [PubMed]

11. Allen, G.C.; Dyke, J.M.; Harris, S.J.; Morris, A. A surface study of the oxidation of type 304L stainless steel at $600 \mathrm{~K}$ in air. Oxid. Met. 1988, 29, 391-408. [CrossRef]

12. Huntz, A.M.; Reckmann, A.; Haut, C.; Sévérac, C.; Herbst, M.; Resende, F.; Sabioni, A. Oxidation of AISI 304 and AISI 439 stainless steels. Mater. Sci. Eng. A 2007, 447, 266-276. [CrossRef]

13. Vesel, A.; Mozetic, M.; Drenik, A.; Hauptman, N.; Balat-Pichelin, M. High temperature oxidation of stainless steel AISI316L in air plasma. Appl. Surf. Sci. 2008, 255, 1759-1765. [CrossRef]

14. Guillamet, R.; Lopitaux, J.; Hannoyer, B.; Lenglet, M. Oxidation of stainless steels (AISI 304 and 316) at high temperature. Influence on the metallic substratum. J. Phys. IV Colloque 1992, 03, C9-349-C9-356. [CrossRef] 


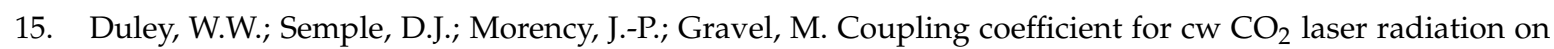
stainless steel. Opt. Laser Technol. 1979, 11, 313-316. [CrossRef]

16. Hales, R. The high temperature oxidation behaviour of austenitic stainless steels. Mater. Corros. 1978, 29, 393-399. [CrossRef]

17. Saito, M.; Furuya, H.; Koga, K.; Sugisaki, M. Effect of Grain Size of Stainless Steel on Oxidation Rate under Oxygen Pressure Controlled by Mo/MoO 2 Oxygen Buffer. J. Nucl. Sci. Technol. 1985, 22, 153-154. [CrossRef]

18. Pantsar, H.; Kujanpää, V. Diode laser beam absorption in laser transformation hardening of low alloy steel. J. Laser Appl. 2004, 16, 147-153. [CrossRef]

19. Brinksmeier, E.; Gläbe, R.; Klocke, F.; Lucca, D.A. Process Signatures-An Alternative Approach to Predicting Functional Workpiece Properties. Procedia Eng. 2011, 19, 44-52. [CrossRef]

20. Brinksmeier, E.; Klocke, F.; Lucca, D.A.; Sölter, J.; Meyer, D. Process Signatures-A New Approach to Solve the Inverse Surface Integrity Problem in Machining Processes. Procedia CIRP 2014, 13, 429-434. [CrossRef]

21. Eckert, S.; Gadeschi, G.B.; Meinke, M.; Vollertsen, F.; Schröder, W. Comparison of laser induced thermal heat impact on $42 \mathrm{CrMo} 4$ in gaseous and liquid ambient. In Proceedings of the 14th International Symposium on Electrochemical Machining Technology (INSECT 2018), Aachen, Germany, 27-28 November 2018; pp. 125-130.

22. Vollertsen, F. Pulvermetallurgische Verarbeitung eines übereutektoiden verschleißfesten Stahls (German); Hanser: München, Germany, 1990; ISBN 3446161333.

23. Bakker, H.; Bonzel, H.P.; Bruff, C.M.; Dayanada, M.A.; Gust, W.; Horváth, J.; Kaur, I.; Kidson, G.V.; Le Claire, A.D.; Mehrer, H.; et al. Diffusion in Solid Metals and Alloys. In Landolt-Börnstein: Numerical Data and Functional Relationships in Science and Technology -New Series Gruppe III: Crystal and Solid State Physics; Mehrer, H., Ed.; Springer: Berlin/Heidelberg, Germany, 1990.

24. Kügler, H.; Vollertsen, F. Determining Absorptivity Variations of Multiple Laser Beam Treatments of Stainless Steel Sheets. J. Manuf. Mater. Process. 2018, 2, 84. [CrossRef]

(C) 2019 by the author. Licensee MDPI, Basel, Switzerland. This article is an open access article distributed under the terms and conditions of the Creative Commons Attribution (CC BY) license (http://creativecommons.org/licenses/by/4.0/). 